\title{
SEGURANÇA DO PACIENTE: ADMINISTRAÇÃO SEGURA DE MEDICAMENTOS
}

\section{Patient safety: drug administration safe}

Poliana do Prado Andrade ${ }^{1}$, Thais da Silva Amaral ${ }^{1}$, Jaqueline Aparecida Erig Omizzolo $^{2}$

${ }^{1}$ Enfermeira, Universidade do Planalto Catarinense - UNIPLAC, Lages/SC.

2 Enfermeira, Mestre em Enfermagem, Professora dos cursos de Enfermagem e Medicina, Universidade do Planalto Catarinense - UNIPLAC, Lages/SC.

\section{Endereço para correspondência:}

Jaqueline Aparecida Erig Omizzolo

Universidade do Planalto Catarinense - UNIPLAC.

Email: jacky-erig@hotmail.com. 


\title{
Resumo
}

Trata-se de uma revisão integrativa de literatura, originada do trabalho de conclusão do curso de Enfermagem da Universidade do Planalto Catarinense. O objetivo geral foi analisar estudos referentes à administração segura de medicamentos ao paciente, no âmbito hospitalar, visando contribuir para uma prática assistencial de enfermagem de qualidade. A etapa metodológica utilizou o método exploratório e descritivo, por meio de pesquisa de natureza de revisão integrativa. Os critérios adotados para seleção dos artigos incluíram todas as categorias de artigos. A estratégia de coleta de dados para identificação e seleção dos estudos foi realizada através do levantamento bibliográfico de manuais nacionais e publicações indexadas nas seguintes bases de dados: Medical Literature Analysis and Retrieval System Online e Scientific Eletronic Library Online, as quais foram acessadas através do portal da Biblioteca Virtual em Saúde. O resultado dessa busca identificou 20 artigos nas bases Medical Literature Analysis and Retrieval System Online e Scientific Eletronic Library Online. Desse total, 13 foram incluídos e 7 excluídos. Concluiu-se que a administração segura de medicamentos exige dos profissionais uma ampla abordagem educativa sobre os eventos adversos para que estes sirvam de aprendizado e não de punição. Ações educativas desenvolvidas na perspectiva de fortalecer a eficiência e eficácia dos processos contribuirão efetivamente para a qualidade na assistência de enfermagem.

Palavras-chave: Enfermagem; Segurança do paciente; Medicação.

\begin{abstract}
This is an integrative review of literature originated from the work on the conclusion of University of Planalto Catarinense nursing course. The general objective was to analyze studies about security administration of medicines to the patient in the clinical ambient aiming to contribute for a nursing assistance practice of quality. The methodological stage utilized the descriptive and exploratory methodology in search of integrative revision nature. The criterions adopted for the selection of articles included all categories of articles. The strategy of dice collected to identification and selection by studies was realized through bibliographical search of national manual and publications in this bases of dice: Medical Literature Analysis and Retrieval
\end{abstract}




\section{Revisão}

\section{Atenção à Saúde}

System Online and Scientific Electronic Library Online, which were accessed through the portal of the Biblioteca Virtual em Saúde. The result of this search identified 20 articles in bases Medical Literature Analysis and Retrieval System Online and Scientific Electronic Library Online. Of this total, 13 were included and 7 were excluded. It was concluded that the safe administration of medicines requires from professionals a comprehensive educational approach to adverse events so they can serve as learning and not as punishment. Educational activities developed in view of strengthening the efficiency and effectiveness of processes will contribute effectively to the quality of nursing care.

Keywords: Nursing; Security of patient; Medicines.

\section{INTRODUÇÃO}

O tema segurança do paciente tornou-se importante desde os tempos de Florence Nightingale, que postulava já em 1859 que, "talvez pareça estranho enunciar como primeiro dever de um hospital não causar mal ao paciente"1. Historicamente, Florence estruturou seu modelo de assistência depois de ter trabalhado no cuidado de soldados durante a Guerra da Criméia, por volta do século XVIII. Quando Florence se preocupou em separar os soldados pelas enfermidades, melhorar o lugar onde eles eram alojados e cuidar da higiene e conforto dos mesmos, ela estava prestando um serviço de qualidade e fazendo a segurança do paciente.

Embora as inovações introduzidas por Nightingale tenham causado impacto direto nos resultados no cuidado de enfermagem prestado aos pacientes em sua época, ainda lutamos para reduzir taxas de mortalidade e de infecção nos hospitais, mesmo em face dos avanços científicos e tecnológicos vividos nas últimas décadas ${ }^{1}$. Assim, há que se entender a segurança do paciente como um problema de saúde antigo, de abrangência mundial, e um imperativo ético no cuidado de enfermagem. Para minimizar esse problema, devem-se promover ações que resultem em transformações no sistema, pois profundas falhas operacionais podem impossibilitar 


\section{Revisão}

\section{Atenção à Saúde}

que os profissionais exerçam a enfermagem que aprenderam e idealizaram para seus pacientes e suas famílias ${ }^{1}$.

Atualmente a segurança do paciente tornou-se tema importante de estudo. $\mathrm{Na}$ perspectiva da enfermagem, a segurança do paciente pode ser definida como assistir ao indivíduo, em esfera individual ou coletiva, respeitando sua individualidade, sua integralidade e sua dignidade enquanto ser humano, atendendo suas necessidades básicas para promoção, manutenção e recuperação da saúde, bem como reabilitação dos efeitos da doença, dentro de um sistema que lhe proporcione proteção contra eventos adversos ${ }^{1}$.

Para promoção da segurança do paciente é necessária a abordagem de todo o sistema de cuidados, pautado em uma filosofia de transparência e de comunicação proativa, não de culpar ou envergonhar o profissional, incorporando medidas que abranjam fatores humanos e situações prejudiciais ${ }^{1}$.

Comunicar os erros é apenas o primeiro passo no processo para reduzi-los, bem como para a melhoria contínua da qualidade. Deve-se atentar à análise e à compreensão da causa dos erros, de forma a se criar sistemas de aprendizagem das equipes, visando melhorar a segurança do paciente. Uma abordagem que costuma ser usada na análise dos fatores humanos é a de incidentes críticos. Ela examina os casos prejudiciais de forma a entender onde o sistema falhou, por que 0 incidente ocorreu e quais foram às circunstâncias envolvidas no incidente ${ }^{1}$.

Destaca-se que o Brasil é um dos países que compõem a Aliança Mundial para a Segurança do Paciente, estabelecida pela Organização Mundial de Saúde (OMS) em 2004. O principal propósito dessa aliança é instituir medidas que aumentem a segurança do paciente e a qualidade dos serviços de saúde, fomentado pelo comprometimento político dos Estados signatários. A qualidade dos serviços de saúde é um elemento determinante para assegurar a redução e o controle dos riscos a que o paciente está submetido. Nesse sentido, um conjunto de ações complementares entre si, incluídas as ações de controle sanitário e regulamentação, são imprescindíveis para identificar precocemente a ocorrência de eventos que afetam a segurança do paciente, reduzir o dano e evitar riscos futuros ${ }^{2}$.

Em 25 de julho de 2013 entrou em vigor a Resolução da Diretoria Colegiada (RDC) n 36, que institui ações para a segurança do paciente em serviços de saúde e dá outras providências ${ }^{3}$. Esta tem como definição ações de notificação e 


\section{Revisão}

\section{Atenção à Saúde}

monitoramento de eventos adversos relacionados tanto aos produtos quanto às falhas nos processos de cuidado. Tal resolução vem permitir a ampliação e a articulação do escopo de notificações de eventos adversos no país. Essa realidade denota a necessidade de organização desse importante processo de trabalho no âmbito do Sistema Nacional de Vigilância Sanitária (SNVS) e das unidades assistenciais que compõem as Redes de Atenção à Saúde.

Dentro desse contexto, o desenvolvimento desse estudo foi motivado a partir de levantamento de dados decorrente de uma atividade pedagógica da disciplina de Projetos de Cuidado Integral, do $8^{-}$semestre do curso de Enfermagem da Universidade do Planalto Catarinense (UNIPLAC), realizado em uma instituição hospitalar local. No referido estudo levantaram-se questões relativas à segurança do paciente, o que estimulou desenvolver este tema como trabalho de curso. $O$ estudo se justifica, uma vez que a equipe de enfermagem é a responsável pela conferência e administração da medicação aos pacientes, bem como a literatura científica ressalta que $39 \%$ dos erros de medicação ocorrem pela prescrição médica, 12\% na transcrição da prescrição e $36 \%$ na administração dos medicamentos ${ }^{4}$.

Esta pesquisa teve como objetivo geral identificar estudos referentes à administração segura de medicamentos ao paciente, no âmbito hospitalar, por meio de publicações em periódicos e manuais nacionais, visando contribuir para uma prática assistencial de enfermagem de qualidade. A pergunta norteadora consistiu em questionar o que os estudos brasileiros apontam como aspectos de cuidado, referentes à administração segura de medicamentos.

\section{MÉTODOS}

Para o desenvolvimento dessa pesquisa, foi utilizado o método exploratório e descritivo, por meio de uma revisão integrativa.

As etapas que compuseram esta revisão foram a elaboração da pergunta norteadora, a busca ou amostragem na literatura/coleta de dados, a análise crítica dos estudos incluídos, a discussão dos resultados e a apresentação da revisão integrativa.

Em relação à amostra, os critérios adotados para seleção dos artigos incluíram todas as categorias de artigos, podendo ser pesquisa original, revisão de 


\section{Revisão}

\section{Atenção à Saúde}

literatura, revisão sistemática, reflexão, atualização, relato de experiência, editorial, entre outros; artigos com resumos e textos completos, disponíveis com acesso gratuito para análise. Ainda foram considerados para a pesquisa manuais e publicações legais referentes ao tema.

Como critérios de inclusão foram usados artigos no idioma português, publicados no período compreendido entre 2009 a 2014 e artigos que continham em seus títulos e/ou resumos os seguintes descritores: medicação, segurança do paciente e enfermagem. Como critérios de exclusão foram considerados as publicações não coincidentes e/ou relacionados ao tema, ou que não se obteve acesso ao texto completo, ou trabalhos repetidos e estudos que não se referiram aos objetivos da pesquisa.

A pesquisa foi desenvolvida entre os meses de maio a novembro de 2014 . A estratégia de coleta de dados para identificação e seleção dos estudos foi realizada através do levantamento bibliográfico de manuais nacionais e publicações indexadas nas seguintes bases de dados: Medical Literature Analysis and Retrieval System Online (MEDLINE) e Scientific Eletronic Library Online (SciELO), as quais foram acessadas através do portal da Biblioteca Virtual da Saúde (BVS). O resultado dessa busca identificou 20 artigos nas bases MEDLINE e SciELO. Desse total, 13 foram incluídos e 7 excluídos.

Para organização e análise dos dados levantados foi elaborado um quadro referente aos principais indicadores dos achados (Quadro 1), contendo título do periódico, ano de publicação, categoria e natureza do estudo, método de análise, principal(is) tema(s) enfocado(s) e conclusão.

$\mathrm{Na}$ etapa de discussão dos resultados foi realizada uma análise temática que, segundo Minayo ${ }^{5}$, "consiste em descobrir os núcleos de sentido que compõem uma comunicação, cuja presença ou frequência signifiquem alguma coisa para o objeto analítico visado".

\section{RESULTADOS}

No Quadro 1 é apresentada a síntese dos estudos identificados e incluídos nessa pesquisa, sendo dispostos por ano de publicação, ordenando do ano mais atual para o menos atual. 
Quadro 1. Síntese dos estudos.

\begin{tabular}{|c|c|c|c|c|c|}
\hline $\begin{array}{l}\text { Título do } \\
\text { periódico }\end{array}$ & $\begin{array}{c}\text { Ano de } \\
\text { publicação }\end{array}$ & $\begin{array}{c}\text { Categoria e } \\
\text { natureza do } \\
\text { estudo }\end{array}$ & $\begin{array}{l}\text { Método de } \\
\text { análise }\end{array}$ & $\begin{array}{l}\text { Principais } \\
\text { temas } \\
\text { enfocados }\end{array}$ & Conclusão \\
\hline $\begin{array}{l}\text { Estratégia para } \\
\text { promover } \\
\text { segurança do } \\
\text { paciente: da } \\
\text { identificação } \\
\text { dos riscos às } \\
\text { práticas } \\
\text { baseadas em } \\
\text { evidências. }\end{array}$ & 2014 & $\begin{array}{l}\text { Estudo } \\
\text { descritivo } \\
\text { quantitativo }\end{array}$ & $\begin{array}{l}\text { Referencial de } \\
\text { Análise de } \\
\text { Conteúdo } \\
\text { segundo } \\
\text { Bardin }\end{array}$ & $\begin{array}{l}\text { - } \\
\text { Gerenciamento } \\
\text { de segurança; } \\
\text { - Qualidade da } \\
\text { assistência }\end{array}$ & $\begin{array}{l}\text { A presente pesquisa } \\
\text { permitiu identificar e } \\
\text { analisar estratégias para } \\
\text { promover a segurança do } \\
\text { paciente no contexto } \\
\text { hospitalar. Percebeu-se } \\
\text { ainda que os profissionais } \\
\text { sabem os riscos aos } \\
\text { quais os pacientes estão } \\
\text { expostos, e isso os } \\
\text { favorece à trabalharem } \\
\text { com mais atenção. } \\
\text { Sugeriu a inclusão e a } \\
\text { participação ativa destes } \\
\text { profissionais em uma } \\
\text { gestão compartilhada } \\
\text { para a implantação da } \\
\text { cultura de segurança. }\end{array}$ \\
\hline $\begin{array}{l}\text { Práticas } \\
\text { assistenciais } \\
\text { para segurança } \\
\text { do paciente em } \\
\text { unidade de } \\
\text { terapia } \\
\text { intensiva. }\end{array}$ & 2014 & $\begin{array}{l}\text { Pesquisa } \\
\text { descritiva }\end{array}$ & $\begin{array}{lr}\text { Teste G de } \\
\text { independência } \\
\text { com } r a \\
\text { correção de } \\
\text { Williams. }\end{array}$ & $\begin{array}{l}\text { Práticas } \\
\text { assistenciais de } \\
\text { enfermagem }\end{array}$ & $\begin{array}{l}\text { Após o estudo concluiu- } \\
\text { se que as boas práticas } \\
\text { assistenciais de } \\
\text { enfermagem para a } \\
\text { segurança do paciente } \\
\text { foram realizadas com } \\
\text { diversidade, conforme o } \\
\text { turno de trabalho. }\end{array}$ \\
\hline $\begin{array}{l}\text { Flebite } \\
\text { associada a } \\
\text { cateteres } \\
\text { intravenosos } \\
\text { periféricos em } \\
\text { crianças: } \\
\text { estudo de } \\
\text { fatores } \\
\text { predisponentes }\end{array}$ & 2014 & $\begin{array}{l}\text { Coorte } \\
\text { retrospectiva. }\end{array}$ & $\begin{array}{l}\text { Frequências } \\
\text { absolutas, } \\
\text { relativas e } \\
\text { medianas. }\end{array}$ & $\begin{array}{l}\text { Fatores que } \\
\text { predispõem a } \\
\text { flebite. }\end{array}$ & $\begin{array}{l}\text { A ocorrência de flebite } \\
\text { não apresentou } \\
\text { associação rom } \\
\text { características } \\
\text { demográficas, e os } \\
\text { aspectos da terapia que } \\
\text { representaram fatores de } \\
\text { risco foram condições } \\
\text { predisponentes para } \\
\text { insucesso da punção, } \\
\text { antecedentes } \\
\text { complicações, de } \\
\text { administração } \\
\text { fármacos e soluções com } \\
\text { extremos de pH e } \\
\text { osmolaridade. }\end{array}$ \\
\hline $\begin{array}{l}\text { Eventos } \\
\text { adversos em } \\
\text { pacientes } \\
\text { cirúrgicos: } \\
\text { conhecimento } \\
\text { dos } \\
\text { profissionais de } \\
\text { enfermagem }\end{array}$ & 2013 & $\begin{array}{l}\text { Pesquisa } \\
\text { descritiva }\end{array}$ & $\begin{array}{l}\text { Os dados } \\
\text { foram } \\
\text { analisados por } \\
\text { técnicas de } \\
\text { estatística } \\
\text { descritiva }\end{array}$ & $\begin{array}{l}\text { Conhecimento } \\
\text { da equipe de } \\
\text { enfermagem } \\
\text { acerca de } \\
\text { eventos } \\
\text { adversos, na } \\
\text { ala cirúrgica. }\end{array}$ & $\begin{array}{l}\text { A enfermagem deve } \\
\text { defender os interesses } \\
\text { dos pacientes, conhecer } \\
\text { os riscos inerentes ao } \\
\text { processo cirúrgico e } \\
\text { alertar os integrantes da } \\
\text { equipe sobre os possíveis } \\
\text { problemas, como eventos } \\
\text { adversos cirúrgicos e as } \\
\text { possíveis causas para } \\
\text { sua ocorrência. }\end{array}$ \\
\hline $\begin{array}{l}\text { Prevalência de } \\
\text { incidentes sem } \\
\text { dano e eventos } \\
\text { adversos em } \\
\text { uma clínica }\end{array}$ & 2013 & $\begin{array}{l}\text { Estudo } \\
\text { transversal } \\
\text { Retrospectivo }\end{array}$ & $\begin{array}{l}\text { Quantitativo, } \\
\text { utilizando } \\
\text { software } \\
\text { Statistical } \\
\text { Package for }\end{array}$ & $\begin{array}{l}\text { Eventos } \\
\text { adversos sem } \\
\text { dano em clínica } \\
\text { cirúrgica }\end{array}$ & $\begin{array}{l}\text { Foram identificados } 5.454 \\
\text { registros de incidentes } \\
\text { sem dano, estimando } \\
\text { prevalência de } 82,0 \% \text {. O } \\
\text { evento adverso foi }\end{array}$ \\
\hline
\end{tabular}




\begin{tabular}{|c|c|c|c|c|c|}
\hline $\begin{array}{l}\text { Título do } \\
\text { periódico }\end{array}$ & $\begin{array}{c}\text { Ano de } \\
\text { publicação }\end{array}$ & $\begin{array}{l}\text { Categoria e } \\
\text { natureza do } \\
\text { estudo }\end{array}$ & $\begin{array}{l}\text { Método de } \\
\text { análise }\end{array}$ & $\begin{array}{l}\text { Principais } \\
\text { temas } \\
\text { enfocados }\end{array}$ & Conclusão \\
\hline cirúrgica & & & $\begin{array}{l}\text { Social } \\
\text { Science } \\
\text { (versão } 17.0 \\
\text { para } \\
\text { Windows) }\end{array}$ & & $\begin{array}{ll}\text { identificado } & \text { em } 218 \\
\text { registros, } & \text { estimando } \\
\text { prevalência de } & 18,7 \% \text {. }\end{array}$ \\
\hline $\begin{array}{l}\text { Compreensão } \\
\text { de alunos de } \\
\text { curso de } \\
\text { graduação em } \\
\text { enfermagem e } \\
\text { medicina sobre } \\
\text { segurança do } \\
\text { paciente }\end{array}$ & 2013 & $\begin{array}{l}\text { Estudo } \\
\text { prospectivo e } \\
\text { exploratório }\end{array}$ & $\begin{array}{l}\text { Técnica de } \\
\text { Delphi }\end{array}$ & $\begin{array}{l}\text { Segurança dos } \\
\text { pacientes sob o } \\
\text { viés de alunos } \\
\text { dos cursos de } \\
\text { graduação em } \\
\text { enfermagem e } \\
\text { medicina. }\end{array}$ & \begin{tabular}{lr}
\multicolumn{3}{l}{ Os alunos demonstraram } \\
serem capazes de \\
relacionar alguns dos \\
aspectos pesquisados \\
sobre segurança do \\
paciente com as \\
experiências vividas nos \\
estágios curriculares.
\end{tabular} \\
\hline $\begin{array}{l}\text { Análise da } \\
\text { administração } \\
\text { de } \\
\text { medicamentos } \\
\text { intravenosos } \\
\text { em hospital da } \\
\text { rede sentinela }\end{array}$ & 2012 & $\begin{array}{l}\text { Pesquisa } \\
\text { transversal de } \\
\text { natureza } \\
\text { observacional } \\
\text { guiada pela } \\
\text { técnica de } \\
\text { observação } \\
\text { com roteiro } \\
\text { sistematizado } \\
\text { tipo checklist }\end{array}$ & $\begin{array}{l}\text { Quantitativo } \\
\text { com } \\
\text { tratamento } \\
\text { estatístico } \\
\text { com medidas } \\
\text { de tendência } \\
\text { central e } \\
\text { dispersão } \\
\text { (banco de } \\
\text { dados no } \\
\text { software Excel } \\
\text { 2007). }\end{array}$ & $\begin{array}{l}\text { - Erros de } \\
\text { medicação; } \\
\text { - Segurança do } \\
\text { paciente }\end{array}$ & $\begin{array}{l}\text { Este estudo revelou em } \\
\text { todos os setores, e em } \\
\text { todas as categorias } \\
\text { envolvidas, altas taxas de } \\
\text { erros, com exceção } \\
\text { daqueles de dose e via, } \\
\text { onde não se encontraram } \\
\text { erros. Mostra a } \\
\text { necessidade de garantir a } \\
\text { segurança do processo } \\
\text { de medicação. O hospital } \\
\text { vem capacitando os } \\
\text { técnicos para um } \\
\text { atendimento mais } \\
\text { humanizado. Traz } \\
\text { também educação } \\
\text { isolada e para a equipe } \\
\text { multiprofissional como } \\
\text { atividade cotidiana. }\end{array}$ \\
\hline $\begin{array}{l}\text { Método } \\
B U N D L E \text { na } \\
\text { redução de } \\
\text { infecção de } \\
\text { corrente } \\
\text { sanguínea } \\
\text { relacionada a } \\
\text { cateteres } \\
\text { centrais: } \\
\text { revisão } \\
\text { integrativa }\end{array}$ & 2012 & $\begin{array}{l}\text { Revisão } \\
\text { Integrativa da } \\
\text { literatura }\end{array}$ & Quantitativo & $B U N D L E$ & $\begin{array}{l}\text { Os } \\
\text { apresentados achados } \\
\text { estudos evidenciaram a } \\
\text { necessidade } \\
\text { realização de mais } \\
\text { trabalhos nessa temática, } \\
\text { com o intuito de } \\
\text { direcionar a prática } \\
\text { clínica de como aplicar e } \\
\text { verificar os resultados do } \\
\text { uso de BUNDLE na } \\
\text { prevenção de infecção de } \\
\text { corrente sanguínea } \\
\text { relacionada ao uso de } \\
\text { Cateter Central de } \\
\text { Inserção Periférica } \\
\text { (CCIP), por se tratar de } \\
\text { uma linha de investigação } \\
\text { de relevância para a } \\
\text { enfermagem pelo fato de } \\
\text { ser a responsável pela } \\
\text { instalação e manutenção } \\
\text { deste tipo de dispositivo. }\end{array}$ \\
\hline $\begin{array}{l}\text { Investigação da } \\
\text { técnica de } \\
\text { preparo de } \\
\text { medicamentos } \\
\text { para } \\
\text { administração } \\
\text { por cateteres }\end{array}$ & 2013 & $\begin{array}{l}\text { Estudo } \\
\text { epidemiológico } \\
\text { transversal, de } \\
\text { natureza } \\
\text { observacional }\end{array}$ & $\begin{array}{l}\text { Quantitativo } \\
\text { classificação } \\
\text { de erro } \\
\text { utilizada pela } \\
\text { National } \\
\text { Coordinating } \\
\text { Council for }\end{array}$ & $\begin{array}{l}\text { Técnica para } \\
\text { preparo de } \\
\text { medicamentos } \\
\text { X Trituração de } \\
\text { medicamentos }\end{array}$ & $\begin{array}{l}\text { Conclui-se que a } \\
\text { trituração indevida pode } \\
\text { ter comprometido no } \\
\text { resultado terapêutico. }\end{array}$ \\
\hline
\end{tabular}




\begin{tabular}{|c|c|c|c|c|c|}
\hline $\begin{array}{l}\text { Título do } \\
\text { periódico }\end{array}$ & $\begin{array}{c}\text { Ano de } \\
\text { publicação }\end{array}$ & $\begin{array}{l}\text { Categoria e } \\
\text { natureza do } \\
\text { estudo }\end{array}$ & $\begin{array}{l}\text { Método de } \\
\text { análise }\end{array}$ & $\begin{array}{l}\text { Principais } \\
\text { temas } \\
\text { enfocados }\end{array}$ & Conclusão \\
\hline $\begin{array}{l}\text { pela } \\
\text { enfermagem na } \\
\text { terapia } \\
\text { intensiva }\end{array}$ & & & $\begin{array}{l}\text { Medication } \\
\text { Error } \\
\text { Reporting } \\
\text { Prevention } \\
\text { (NNC MERP) }\end{array}$ & & \\
\hline $\begin{array}{l}\text { Segurança do } \\
\text { paciente: } \\
\text { análise do } \\
\text { preparo de } \\
\text { medicação } \\
\text { intravenosa em } \\
\text { hospital da rede } \\
\text { sentinela }\end{array}$ & 2011 & $\begin{array}{l}\text { Pesquisa } \\
\text { transversal de } \\
\text { natureza } \\
\text { observacional }\end{array}$ & $\begin{array}{l}\text { Classificação } \\
\text { do erro pelo } \\
\text { NCC MERP } \\
\text { (National } \\
\text { Coordinating } \\
\text { Council for } \\
\text { Medication } \\
\text { Error } \\
\text { Reporting } \\
\text { Prevention - } \\
\text { órgão norte- } \\
\text { americano } \\
\text { criado para } \\
\text { maximizar o } \\
\text { uso racional } \\
\text { de } \\
\text { medicamento) }\end{array}$ & $\begin{array}{l}\text { - Erros de } \\
\text { medicação; } \\
\text { - Métodos de } \\
\text { segurança }\end{array}$ & $\begin{array}{l}\text { Este estudo amplia } 0 \\
\text { conhecimento sobre o } \\
\text { processo de preparo de } \\
\text { medicações pela } \\
\text { enfermagem e oferece } \\
\text { elementos para contribuir } \\
\text { para o processo de } \\
\text { cuidado em saúde, } \\
\text { visando melhorar a } \\
\text { qualidade das } \\
\text { assistências prestadas ao } \\
\text { paciente, promovendo o } \\
\text { uso seguro e racional de } \\
\text { medicamentos } \\
\text { subsidiando práticas que } \\
\text { evidenciem cada vez } \\
\text { menos erros. }\end{array}$ \\
\hline $\begin{array}{l}\text { Capacitação de } \\
\text { enfermeiros } \\
\text { para uso de } \\
\text { ultrassonografia } \\
\text { na punção } \\
\text { intravascular } \\
\text { periférica. }\end{array}$ & 2010 & $\begin{array}{l}\text { Aplicação de } \\
\text { estratégia } \\
\text { educacional: } \\
\text { capacitação }\end{array}$ & $\begin{array}{l}\text { Capacitação } \\
\text { teórico- } \\
\text { prática, parte } \\
\text { de uma etapa } \\
\text { de projeto de } \\
\text { pesquisa } \\
\text { realizado com } \\
\text { fomento do } \\
\text { CNPq. }\end{array}$ & $\begin{array}{l}\text { - Segurança do } \\
\text { paciente; } \\
\text { - Infusão } \\
\text { intravenosa; } \\
\text { - } \\
\text { Ultrassonografia } \\
\text { e Doppler; } \\
\text { - Punção } \\
\text { intravascular } \\
\text { periférica; } \\
\text { - Terapia } \\
\text { intravenosa }\end{array}$ & $\begin{array}{l}\text { Inovação na prática da } \\
\text { enfermagem no uso do } \\
\text { Ultrassom (US) para } \\
\text { guiar punções vasculares } \\
\text { periféricas. A capacitação } \\
\text { auxiliou um melhor } \\
\text { preparo dos profissionais } \\
\text { no uso dessa tecnologia, } \\
\text { promovendo assim } \\
\text { práticas inovadoras de } \\
\text { enfermagem } \\
\text { fundamentadas } \\
\text { evidências. }\end{array}$ \\
\hline $\begin{array}{l}\text { Condutas } \\
\text { adotadas por } \\
\text { técnicos de } \\
\text { enfermagem } \\
\text { após ocorrência } \\
\text { de erros de } \\
\text { medicação }\end{array}$ & 2010 & $\begin{array}{l}\text { Estudo } \\
\text { descritivo } \\
\text { quantitativo }\end{array}$ & $\begin{array}{ll}\text { Análise } & \text { de } \\
\text { conteúdo } & \\
\text { segundo } & \\
\text { Bardin. } & \end{array}$ & $\begin{array}{l}\text { - Erros de } \\
\text { medicação; } \\
\text { - Cuidados de } \\
\text { enfermagem; } \\
\text { - Imperícia; } \\
\text { - Condutas de } \\
\text { enfermagem }\end{array}$ & $\begin{array}{l}\text { Após o estudo os autores } \\
\text { ressaltam a necessidade } \\
\text { de que as instituições de } \\
\text { saúde adotem uma } \\
\text { cultura de transparência } \\
\text { em relação aos erros de } \\
\text { medicação com a criação } \\
\text { de políticas e e } \\
\text { padronização para } \\
\text { notificar, divulgar e } \\
\text { fortalecer medidas } \\
\text { preventivas. }\end{array}$ \\
\hline $\begin{array}{l}\text { Erros de } \\
\text { medicação e } \\
\text { qualidade de } \\
\text { vida } \\
\text { relacionada à } \\
\text { saúde de } \\
\text { profissionais de } \\
\text { enfermagem } \\
\text { em unidades de } \\
\text { terapia } \\
\text { intensiva }\end{array}$ & 2010 & $\begin{array}{l}\text { Trata-se de } \\
\text { um estudo } \\
\text { observacional } \\
\text { e transversal, } \\
\text { com } \\
\text { abordagem } \\
\text { quantitativa }\end{array}$ & $\begin{array}{l}\text { Quantitativo; } \\
\text { As análises } \\
\text { estatísticas } \\
\text { foram } \\
\text { efetuadas nos } \\
\text { programas } \\
\text { SPSS } \\
\text { (Statistical } \\
\text { Package for } \\
\text { the Social } \\
\text { Sciences) for } \\
\text { Windows } 12.0 \\
\text { e Stata } 8.0 \text {. }\end{array}$ & $\begin{array}{l}\text { Reflexo dos } \\
\text { erros na } \\
\text { qualidade de } \\
\text { vida dos } \\
\text { profissionais } \\
\text { que trabalham } \\
\text { em UTIs. }\end{array}$ & $\begin{array}{l}\text { Neste estudo, } \\
\text { prevalência de erros de } \\
\text { medicação em UTI, } \\
\text { relatados } \\
\text { profissionais } \\
\text { enfermagem, foi de } 28 \\
\text { erros durante as quatro } \\
\text { semanas anteriores à } \\
\text { coleta de dados. } \\
\text { Observou-se que, dos } 94 \\
\text { participantes, } 18 \text { se } \\
\text { envolveram com erros de } \\
\text { medicação, sendo seis } \\
\text { enfermeiros e } 12 \text { técnicos } \\
\text { de enfermagem (19\% dos }\end{array}$ \\
\hline
\end{tabular}




\begin{tabular}{|l|c|c|c|c|c|}
\hline $\begin{array}{c}\text { Título do } \\
\text { periódico }\end{array}$ & $\begin{array}{c}\text { Ano de } \\
\text { publicação }\end{array}$ & $\begin{array}{c}\text { Categoria e } \\
\text { natureza do } \\
\text { estudo }\end{array}$ & $\begin{array}{c}\text { Método de } \\
\text { análise }\end{array}$ & $\begin{array}{c}\text { Principais } \\
\text { temas } \\
\text { enfocados }\end{array}$ & Conclusão \\
\hline & & & & $\begin{array}{l}\text { profissionais } \\
\text { participantes). }\end{array}$ \\
\hline
\end{tabular}

Fonte: Próprio Autor

Os dados apresentados passam a ser analisados por aproximação temática elaborada com base na proposta da análise temática de Minayo ${ }^{5}$, sendo organizados por núcleos de sentido. Foram compostos três núcleos.

O primeiro, intitulado (a) segurança do paciente: processos medicamentosos $e$ erros de medicação, abrange temas relacionados à administração de medicamentos em hospitais, as condutas após os erros de medicação e as estratégias e práticas visando a segurança do paciente. Para a composição deste núcleo foram considerados 4 artigos.

O segundo intitula-se (b) segurança do paciente: educação em saúde e estratégias e práticas de segurança do paciente, e reúne os achados relacionados a estratégias e práticas visando a segurança do paciente e a educação e compreensão dos profissionais da saúde. Para a composição deste núcleo foram considerados 4 artigos.

O terceiro e último núcleo intitula-se (c) segurança do paciente: setores críticos, e aborda assuntos relativos a eventos adversos no âmbito de unidade de terapia intensiva e de centro cirúrgico. Para a composição deste núcleo foram considerados 5 artigos.

\section{(a) Segurança do paciente: processos medicamentosos e erros de medicação}

Nos estudos relacionados à medicação intravenosa no âmbito hospitalar, pode-se observar que a segurança do paciente tem gerado muitos debates em âmbito mundial. Este assunto tem recebido várias interpretações, entre elas as associadas à assistência em saúde até um mínimo aceitável, sendo este mínimo aquilo que é viável diante do conhecimento atual. Também, que a eficácia terapêutica pode ser afetada quando não se garante estabilidade química e física, o que pode causar danos ao paciente ${ }^{6}$.

O estudo de Lisboa, Silva e Matos ${ }^{7}$, relacionado à identificação dos erros cometidos durante o preparo dos medicamentos, em especial os administrados por 


\section{Revisão}

\section{Atenção à Saúde}

cateteres, denota que a trituração indevida compromete o resultado terapêutico. Isso se identificou tanto na não diluição de xaropes, contribuindo para a obstrução de cateteres, quanto nas misturas de medicamentos triturados, os quais podem aumentar o risco de interações farmacêuticas.

Em outro estudo que analisou a frequência de erros ocorridos durante o preparo de medicamentos, Camerini e Silva ${ }^{8}$ identificaram, em doses preparadas por técnicos de enfermagem, uma taxa de erro acima de 70,00\%. Tais erros foram relacionados à troca de agulhas, desinfecção de ampolas, limpeza de bancada, hora e doses erradas.

Ainda sobre as condutas adotadas por técnicos de enfermagem após a ocorrência de erros de medicação, aponta-se que devem ser elaboradas medidas preventivas para evitar a nova ocorrência desses eventos adversos. Tais medidas incluem a comunicação do erro e a observação do paciente, visando, neste caso, minimizar as consequências causadas. Há estudos que afirmam, ainda, a necessidade iminente das instituições de saúde adotarem como prática, em relação à conduta frente aos erros de medicação, políticas e padronizações de notificação. Também sugerem o fortalecimento de ações de educação permanente e implementação de comissões de segurança do paciente, entre outros ${ }^{9}$.

\section{(b) Segurança do paciente: educação em saúde, estratégias e práticas de segurança do paciente.}

Os artigos que compõem esta categoria apontam que, em relação às estratégias e práticas adotadas visando à segurança do paciente, a enfermagem deve estar sempre alerta e propondo soluções inovadoras.

Neste sentido, o estudo de Oliveira et al. ${ }^{10}$ identificou e analisou estratégias para a promoção da segurança do paciente, no que tange a prática dos enfermeiros assistenciais. Os resultados apontaram que, nesta categoria profissional, os erros mais frequentes ocorrem na administração de medicamentos, na transferência de paciente e na troca de informações, no trabalho em equipe e comunicação, na incidência de identificação do paciente, entre outros. A assistência isenta de riscos e falhas ao paciente é um objetivo a ser atingido pelos profissionais da saúde e um compromisso da formação profissional. Com a equipe de enfermagem não é 
diferente, pois erros podem acontecer, exigindo dos enfermeiros condutas imediatas $^{10}$.

Em relação às estratégias e práticas de segurança do paciente adotadas em instituições de saúde, Brachine, Peterline e Pedreira ${ }^{11}$ destacam estudos que abordaram intervenções baseadas em evidência que compõem o método Bundle, voltando-se a redução de infecções na corrente sanguínea. Tal método trata-se de uma prática clínica em forma de pacote ou conjunto de intervenções, formados por um pequeno grupo de cuidados específicos. Os autores destacam questões importantes, como a infecção relacionada a cateteres intravenosos e apontam que esses são dispositivos de suma importância no âmbito hospitalar atualmente ${ }^{11}$.

Já em relação aos aspectos pontuados sobre a educação e compreensão dos profissionais da saúde sobre o tema segurança do paciente, Avelar et al. ${ }^{12}$ descrevem em seu estudo que programas de capacitação de profissionais de saúde devem contemplar conteúdos teóricos, demonstrações práticas e avaliações periódicas de conhecimentos e habilidades. Isso visa desenvolver competências que Ihe possibilitem realizar os procedimentos e intervenções de maneira eficaz, efetiva e segura ${ }^{12}$.

Neste mesmo viés, Yoshikawa et al. ${ }^{13}$, em seu estudo, identificaram a compreensão de alunos de cursos de graduação em enfermagem e medicina de uma universidade pública sobre erro humano e segurança do paciente. Os resultados apontaram que a maior parte dos alunos obteve aprendizado formal sobre esse tema e apresentou atitudes que demonstraram incerteza no que seria correto em relação a algumas práticas. Os autores destacam também que os alunos demonstraram capacidade de relacionar alguns dos aspectos pesquisados sobre segurança do paciente com as experiências vividas nos estágios curriculares. Um exemplo foi a compreensão de que, após um erro cometido, deve-se implementar uma estratégia de prevenção para que não ocorra mais este erro ${ }^{13}$.

\section{(c) Segurança do paciente: setores críticos}

Nos artigos que compõem este núcleo de sentido, os estudos voltaram-se para os setores de unidade de terapia intensiva adulta e pediátrica e centro cirúrgico. 
Barbosa et al. ${ }^{14}$ buscaram verificar em seu estudo boas práticas assistenciais de enfermagem para a segurança do paciente em unidade de terapia intensiva. A partir da análise de um conjunto de 3 itens gerais de boas práticas neste setor, quais sejam, a higiene e conforto, a identificação e prevenção de quedas e 0 controle/prevenção de infecção hospitalar, concluíram que estas são realizadas com um índice de $80 \%$. A exceção ficou voltada à mudança de decúbito, sendo destacado como o cuidado com menor índice de realização. Já em relação aos erros envolvendo medicamentos, verificaram que estes ocorrem com grande frequência em hospitais. Estes erros são classificados como eventos adversos previsíveis, podendo ou não gerar danos aos pacientes. Afirmam que ocorre, em média, um erro de medicação por dia ${ }^{4}$.

Ainda no âmbito da terapia intensiva, há o estudo de Pelliciotti e Kimura ${ }^{15}$, que mostra a relação entre os erros de medicação e qualidade de vida dos profissionais de enfermagem. Os resultados apontaram que 18 dos profissionais participantes da pesquisa cometeram erro e o relataram, e, por sua vez, esses profissionais apresentaram índices de saúde piores quando comparados aos que não relataram erro ${ }^{15}$.

No ambiente do centro cirúrgico, enfoca-se o estudo de Bohomol e Tartali ${ }^{16}$, que verificou o conhecimento da equipe de enfermagem sobre eventos adversos. Apontam como causas frequentes desses eventos, a rotina na programação de procedimentos eletivos e a comunicação ineficaz entre a equipe de enfermagem e médica. Também destacam que a segurança do paciente não é compreendida como uma responsabilidade da equipe multiprofissional. Concluem que o cuidado integral e a qualidade à saúde dependem de uma comunicação eficaz entre os profissionais $^{16}$.

Em um estudo que objetivou identificar os fatores de risco para flebite relacionada a cateteres intravenosos periféricos (CIP) em crianças, em uma unidade cirúrgica pediátrica, Jacinto et al. ${ }^{17}$ destacam questões relacionadas a terapia intravenosa (TIV). Esta é definida por Jacinto et al. ${ }^{17}$ como um conjunto de conhecimentos e técnicas que visam à administração de soluções ou fármacos no sistema circulatório. $\mathrm{O}$ estudo conclui que as complicações de terapia intravenosa podem ser sistêmicas ou locais. Como sistêmicas pode-se citar a septicemia, sobrecarga circulatória, edema pulmonar, embolias e choques. Como complicações 


\section{Revisão}

\section{Atenção à Saúde}

locais as infiltrações, extravasamentos, flebites, hematomas, entre outras. Nesse contexto, a flebite é uma das complicações mais frequentes relacionadas a cateteres intravenosos. Pode ser agrupada em química, quando há relação com a administração de medicamentos, ou infecciosa, quando há contaminação da solução ou do local da inserção do cateter e dispositivo ${ }^{17}$.

Sobre os eventos adversos no âmbito cirúrgico, o estudo de Paranaguá et al. ${ }^{18}$ objetivou estimar a prevalência de incidentes sem dano e eventos adversos em uma clínica cirúrgica. Destaca-se que os eventos mais recorrentes foram relacionados ao processo clínico, em especial à dor aguda em pós-operatório, exigindo substituição ou adição de terapia medicamentosa. Já a retirada não programada dos dispositivos tubulares resultou em procedimento adicional, como reimplantação de cateter, sonda e/ou dreno, nova punção e aumento do tempo dispensado para a assistência ao paciente. Os autores também destacaram que as falhas nos procedimentos técnicos foram relacionadas à inabilidade profissional, resultando em intervenção cirúrgica, maior tempo de internação, abaulamento ou hematoma em local de punção, lesão mecânica por posição inadequada de traqueostomia e óbito ${ }^{18}$.

\section{CONCLUSÃO}

Os achados bibliográficos mostraram que, em relação aos processos medicamentosos e erros de medicação, pode-se constatar que a maior ocorrência destes é em hospitais, sendo os eventos adversos previsíveis.

Sobre as estratégias e práticas seguras de administração de medicamentos, os artigos encontrados destacam que os erros mais frequentes ocorrem nas atividades relacionadas à administração de medicamentos, nos processos de comunicação da equipe de saúde, bem como nas formas de identificação do paciente.

Já em relação à segurança do paciente e à administração de medicamentos em setores críticos, os estudos demonstraram que as falhas ocorrem, em geral, em procedimentos técnicos, caracterizando a inabilidade de profissionais. Um exemplo disso são os abaulamentos ou hematomas e flebites ocorridos nos locais de punção. 
Os aspectos de cuidado referentes à administração segura de medicamentos apontados nos achados destacam a necessidade de uma assistência de enfermagem ainda mais segura. Isso pode ocorrer a partir de ações voltadas para a educação permanente no ambiente de trabalho, focando especialmente no desenvolvimento de uma consciência de notificação de eventos adversos, para que estes possam fortalecer a assistência. Tal ação deve ser realizada de modo a não intimidar ou simplesmente punir os profissionais, mas sim orientá-los na perspectiva da eficiência e eficácia dos processos, culminando na melhoria da qualidade da assistência de enfermagem.

Esse amplo e sempre atual tema não se esgota com esta análise, ao contrário, com este estudo deseja-se estimular e incentivar a produção de novos conhecimentos que auxiliem na prática segura da administração de medicamentos.

\section{REFERÊNCIAS}

1. Pedreira ML. Enfermagem dia a dia: Segurança do paciente. São Caetano do Sul: Yendis; 2009.

2. Instituto Racine. Brasil Faz Parte da Aliança Mundial para a Segurança do Paciente Estabelecida pela OMS [Internet]. 2013 [cited 2015 Jul 12]. Available from: http://www.racine.com.br/ir/brasil-faz-parte-da-alianca-mundial-para-a-seguranca-dopaciente-estabelecida-pela-oms/

3. Brasil. RDC No 36, de 25 de Julho de 2013. Diário Of União. 2013 Jul 26;

4. Fonseca AS, Luis Peterlini F, Costa DA. Segurança do Paciente. São Paulo: Martinari; 2014. 257 p.

5. Minayo MCS. O desafio do conhecimento: pesquisa qualitativa em saúde. 12th ed. São Paulo: Hucitec; 2010.

6. Silva LD, Camerini FG. Análise da administração de medicamentos intravenosos em hospital da rede sentinela. Texto Contexto - Enferm. 2012 Sep;21(3):633-41.

7. Lisboa CD, Silva LD, Matos GC. Investigação da técnica de preparo de medicamentos para administração por cateteres pela enfermagem na terapia intensiva. Rev Esc Enferm USP. 2013 Feb;47(1):53-60.

8. Camerini FG, Silva LD. Segurança do paciente: análise do preparo de medicação intravenosa em hospital da rede sentinela. Texto Amp Contexto - Enferm. 2011 Mar;20(1):41-9. 


\section{Atenção à Saúde}

9. Santos JO, Silva AEBC, Munari DB, Miasso Al. Condutas adotadas por técnicos de enfermagem após ocorrência de erros de medicação. Acta Paul Enferm. 2010 Jun;23(3):328-33.

10. Oliveira RM, Leitão IMTA, Silva LMS, Figueiredo SV, Sampaio RL, Gondim MM, et al. Estratégias para promover segurança do paciente: da identificação dos riscos às práticas baseadas em evidências. Esc Anna Nery. 2014 Mar;18(1):122-9.

11. Brachine JDP, Peterlini MAS, Pedreira MLG. Método bundle na redução de infecção de corrente sanguínea relacionada a cateteres centrais: revisão integrativa. Rev Gaúcha Enferm. 2012 Dec;33(4):200-10.

12. Avelar AFM, Peterlini MAS, Onofre PS de C, Pettengill MAM, Pedreira M da LG. Capacitação de enfermeiros para uso da ultrassonografia na punção intravascular periférica. Acta Paul Enferm. 2010 Jun;23(3):433-6.

13. Yoshikawa JM, Sousa BEC, Peterlini MAS, Kusahara DM, Pedreira M da LG, Avelar AFM. Compreensão de alunos de cursos de graduação em enfermagem e medicina sobre segurança do paciente. Acta Paul Enferm. 2013;26(1):21-9.

14. Barbosa TP, Oliveira GAA, Lopes MNA, Poletti NAA, Beccaria LM, Barbosa TP, et al.. Práticas assistenciais para segurança do paciente em unidade de terapia intensiva. Acta Paul Enferm. 2014 Jun;27(3):243-8.

15. Pelliciotti JSS, Kimura M. Erros de medicação e qualidade de vida relacionada à saúde de profissionais de enfermagem em unidades de terapia intensiva. Rev Latinoam Enferm. 2010 Dec;18(6):1062-9.

16. Bohomol E, Abreu Tartali J. Eventos adversos em pacientes cirúrgicos: conhecimento dos profissionais de enfermagem. Acta Paul Enferm. 2013;26(4):37681.

17. Jacinto AKL, Avelar AFM, Wilson AMMM, Pedreira MLG, Jacinto AKL, Avelar AFM, et al.. Flebite associada a cateteres intravenosos periféricos em crianças: estudo de fatores predisponentes. Esc Anna Nery. 2014 Jun;18(2):220-6.

18. Paranaguá TTB, Bezerra ALQ, Silva AEBC, Azevedo Filho FM. Prevalência de incidentes sem dano e eventos adversos em uma clínica cirúrgica. Acta Paul Enferm. 2013;26(3):256-62. 